NASA/TM—2016-219066

\title{
Model-Based Engine Control Architecture With an Extended Kalman Filter
}

Jeffrey T. Csank and Joseph W. Connolly

Glenn Research Center, Cleveland, Ohio 


\section{NASA STI Program . . . in Profile}

Since its founding, NASA has been dedicated to the advancement of aeronautics and space science. The NASA Scientific and Technical Information (STI) Program plays a key part in helping NASA maintain this important role.

The NASA STI Program operates under the auspices of the Agency Chief Information Officer. It collects, organizes, provides for archiving, and disseminates NASA's STI. The NASA STI Program provides access to the NASA Technical Report Server-Registered (NTRS Reg) and NASA Technical Report ServerPublic (NTRS) thus providing one of the largest collections of aeronautical and space science STI in the world. Results are published in both non-NASA channels and by NASA in the NASA STI Report Series, which includes the following report types:

- TECHNICAL PUBLICATION. Reports of completed research or a major significant phase of research that present the results of NASA programs and include extensive data or theoretical analysis. Includes compilations of significant scientific and technical data and information deemed to be of continuing reference value. NASA counter-part of peer-reviewed formal professional papers, but has less stringent limitations on manuscript length and extent of graphic presentations.

- TECHNICAL MEMORANDUM. Scientific and technical findings that are preliminary or of specialized interest, e.g., "quick-release" reports, working papers, and bibliographies that contain minimal annotation. Does not contain extensive analysis.
- CONTRACTOR REPORT. Scientific and technical findings by NASA-sponsored contractors and grantees.

- CONFERENCE PUBLICATION. Collected papers from scientific and technical conferences, symposia, seminars, or other meetings sponsored or co-sponsored by NASA.

- SPECIAL PUBLICATION. Scientific, technical, or historical information from NASA programs, projects, and missions, often concerned with subjects having substantial public interest.

- TECHNICAL TRANSLATION. Englishlanguage translations of foreign scientific and technical material pertinent to NASA's mission.

For more information about the NASA STI program, see the following:

- Access the NASA STI program home page at http://www.sti.nasa.gov

- E-mail your question to help@sti.nasa.gov

- $\quad$ Fax your question to the NASA STI Information Desk at 757-864-6500

- Telephone the NASA STI Information Desk at 757-864-9658

- Write to:

NASA STI Program

Mail Stop 148

NASA Langley Research Center Hampton, VA 23681-2199 
NASA/TM-2016-219066

\section{Model-Based Engine Control Architecture With an Extended Kalman Filter}

Jeffrey T. Csank and Joseph W. Connolly

Glenn Research Center, Cleveland, Ohio

Prepared for the

Scitech 2016

sponsored by the American Institute of Aeronautics and Astronautics

San Diego, California, January 4-8, 2016

National Aeronautics and

Space Administration

Glenn Research Center

Cleveland, Ohio 44135 


\section{Acknowledgments}

The authors would like to thank Donald L. Simon for his assistance in developing the optimal tuner extended Kalman filter and the Transformative Tools and Technology project for continuing to advance research in model-based engine control.

Trade names and trademarks are used in this report for identification only. Their usage does not constitute an official endorsement, either expressed or implied, by the National Aeronautics and Space Administration.

Level of Review: This material has been technically reviewed by technical management.

Available from

NASA STI Program

Mail Stop 148

NASA Langley Research Center

Hampton, VA 23681-2199
National Technical Information Service 5285 Port Royal Road Springfield, VA 22161

703-605-6000

This report is available in electronic form at http://www.sti.nasa.gov/ and http://ntrs.nasa.gov/ 


\title{
Model-Based Engine Control Architecture With an Extended Kalman Filter
}

\author{
Jeffrey T. Csank and Joseph W. Connolly \\ National Aeronautics and Space Administration \\ Glenn Research Center \\ Cleveland, Ohio 44135
}

This paper discusses the design and implementation of an extended Kalman filter (EKF) for model-based engine control (MBEC). Previously proposed MBEC architectures feature an optimal tuner Kalman Filter (OTKF) to produce estimates of both unmeasured engine parameters and estimates for the health of the engine. The success of this approach relies on the accuracy of the linear model and the ability of the optimal tuner to update its tuner estimates based on only a few sensors. Advances in computer processing are making it possible to replace the piece-wise linear model, developed off-line, with an on-board nonlinear model running in real-time. This will reduce the estimation errors associated with the linearization process, and is typically referred to as an extended Kalman filter. The nonlinear extended Kalman filter approach is applied to the Commercial Modular Aero-Propulsion System Simulation 40,000 (C-MAPSS40k) and compared to the previously proposed MBEC architecture. The results show that the EKF reduces the estimation error, especially during transient operation.

\section{Nomenclature}

$\begin{array}{ll}A, A_{x q}, B, B_{x q}, & \\ C, C_{x q}, D, D_{x q}, & \\ F, F_{x q}, G, L, M, N & \text { System Matrices } \\ \text { CMAPSS40k } & \text { Commercial Modular Aero-Propulsion System Simulation 40k } \\ \text { EKF } & \text { Extended Kalman filter } \\ \text { Fn } & \text { Thrust estimation error } \\ \text { Fn } & \text { Measured thrust } \\ \text { HPCSM } & \text { High pressure compressor surge margin estimation error } \\ K_{\infty} & \text { Kalman filter gain } \\ \text { MBEC } & \text { Model based engine control } \\ \text { OTEKF } & \text { Optimal tuner extended Kalman filter } \\ \text { OTKF } & \text { Optimal tuner Kalman filter } \\ P_{\infty} & \text { Kalman filter state estimation covariance matrix } \\ \text { T40 } & \text { High pressure turbine inlet temperature estimation error } \\ \text { T40y } & \text { High pressure turbine inlet temperature } \\ V^{*} & \text { Transformation matrix relating } h_{k} \text { to } q_{k} \\ h_{k} & \text { Health parameter vector } \\ q_{k} & \text { Kalman filter tuning parameter } \\ u_{k} & \text { Control input vector } \\ w_{k}, w_{h, k}, w_{q h, k} & \text { Process noise vectors } \\ x_{k} & \text { State vector } \\ x_{h, k} & \text { Augmented state vector }\left(x_{k} \text { and } h_{k}\right) \\ x_{x q, k} & \text { Reduced-order state vector }\left(x_{k} \text { and } q_{k}\right) \\ y_{k} & \text { Vector of measured outputs } \\ z_{k} & \text { Vector of unmeasured (auxiliary) outputs } \\ & \end{array}$




\section{Introduction}

The National Aeronautics and Space Administration Transformational Tools and Technologies project of the Transformative Aeronautics Concepts Program is advancing state-of-the-art computational and experimental tools and technologies that are vital to aviation applications. The project is investing in developing innovative controls techniques that can support and enable concept development and benefits across multiple Aeronautics Research Mission Directorate programs. Under this effort, model based engine control (MBEC) is being investigated as a way to increase engine efficiency without significantly impacting the safety or risk of a failure (Refs. 1 and 2). This is accomplished by allowing the engine to be designed, and operated, with less margin. Engine design margins are established to ensure safe operation under worst case conditions; mainly end-of-life with maximum uncertainty in measured variables. With accurate information of the current engine operating condition, control strategies can be developed to allow the engine to operate more efficiently with the same risk and less margin while still avoiding the violation of any constraints, such as compressor surge.

Traditional commercial aircraft engine control architectures rely on sensed data to provide the aircraft with the requested power (thrust) and assure the engine does not exceed any of its physical (pressures, temperatures, rotor speeds) or operational (surge margin) limits. Some of the principal engine parameters are unmeasured, such as thrust, high-pressure turbine inlet temperature, and compressor surge margin; for which representative engine parameters and relationships are used instead. For example, since thrust is not measured in flight, current commercial aircraft engines regulate the fan speed or engine pressure ratio; both have a direct relationship with thrust (Refs. 3 and 4). Several methods have been proposed to avoid a high-pressure compressor surge (Ref. 5). One solution is to limit the acceleration of the high-pressure spool. However, as the engine degrades, the relationship between the measured engine outputs and the unmeasured engine parameters tend to breakdown and lead to degraded performance and operability. To overcome this issue, MBEC is being used to accurately estimate parameters of interest across the engine life cycle by optimally mapping the numerous health parameters of the engine to the few available onboard sensors.

The high-level MBEC architecture is comprised of three main components; an engine or "truth" model, an on-board model to provide real-time estimates of unmeasured parameters, and finally a controller with limit protection logic. A high-level diagram of the MBEC architecture is shown in Figure 1. In this architecture, the onboard model utilizes actuator commands and measured engine outputs to produce estimated engine parameters regulated by the controller. For the work presented in this paper as well as the previous work (Refs. 1 and 2), the Commercial Modular Aero-Propulsion System Simulation 40k (CMAPSS40k) (Ref. 6) serves as the engine "truth" model and the simulation platform to investigate the MBEC architecture. CMAPSS40k is a high-fidelity, high bypass turbofan simulation developed by NASA.

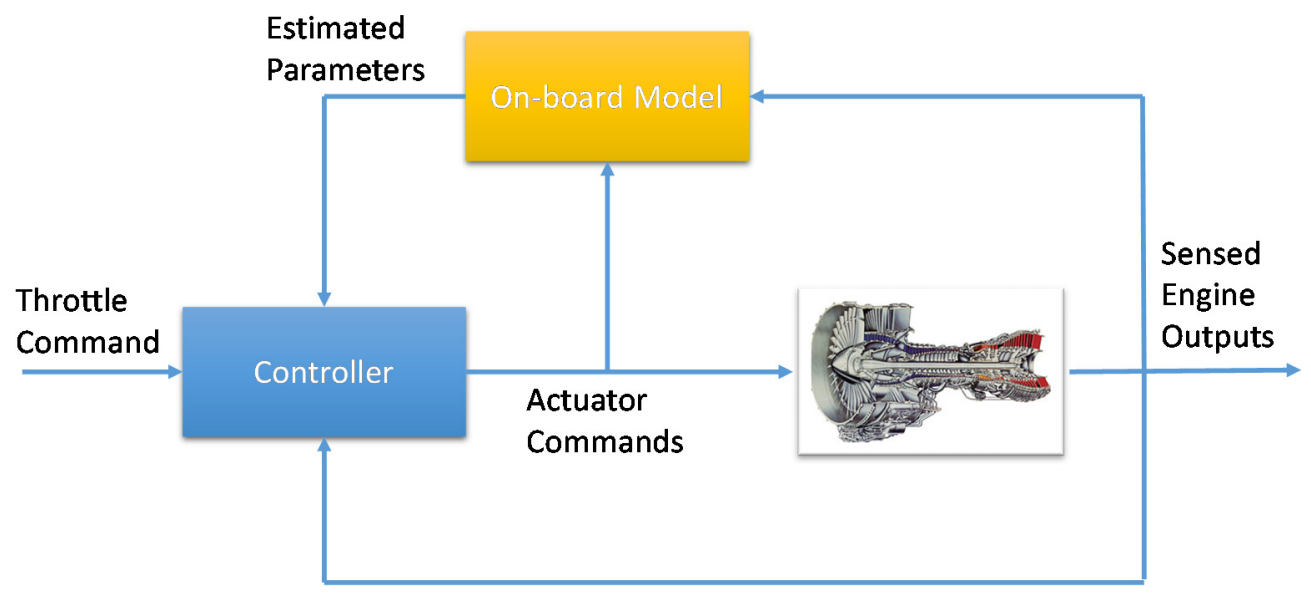

Figure 1.-The MBEC control architecture. 
MBEC has several potential benefits. As noted in Reference 9, a leading benefit is the safe reduction of conservatism in the design related to the use of unmeasured variables. This reduction in the conservatism could allow the engine to be designed to operate at a higher efficiency and ultimately reduce the thrust specific fuel consumption (TSFC). In fault detection applications, the difference between measured and predicted engine outputs, known as residuals, are analyzed to determine if a fault is present in the engine. The residual thresholds are set high enough to avoid false alarms due to modeling errors and low enough to catch engine faults early. The lower the modeling error, the quicker faults can be identified and with higher confidence of a true fault rather than a false alarm due to modeling error.

Other work includes implementing a tracking filter (Ref. 7), the use of genetic algorithms as an input selector for a radial basis function neural network (Ref. 8), and a simplified real time model with an extended Kalman filter (Ref. 9) to produce estimates of unmeasured performance parameters. In the previous NASA MBEC work (Refs. 1 and 2), an optimal tuner Kalman Filter (OTKF) (Ref. 10) was implemented as the on-board model providing estimates of thrust, high pressure turbine inlet temperature, and surge margin. This work focuses on the on-board model portion of the MBEC architecture, in which the OTKF is replaced by an extended Kalman filter and an Optimal Tuner Extended Kalman Filter. With the preceding approach, when a new signal is added to the control system the designer would be required to update the piecewise linear model, Kalman Filter and optimization algorithms; and the flight software would have to be recertified. Alternatively, adding all possible outputs to the piecewise linear model look-up table would require massive memory-storage space and would increase the cost of the controller. If a full nonlinear model was implemented onboard, the designer would only have to make a change to the current code.

Section II discusses the current OTKF strategy. Section III discusses the implementation of the extended Kalman filter and the Optimal Tuner Kalman filter. Results are shown in Section IV followed by conclusions in Section V.

\section{General Linear Optimal Tuner Kalman Filter Approach}

For MBEC to be successfully applied for aircraft engine control, an accurate estimate of the desired unmeasured engine parameters must exist. Estimating unmeasured engine parameters is complicated by the fact that the engine's performance is affected by the level of degradation. Degradation, or health of the engine, is commonly described by unmeasured health parameters that relate to the efficiency and flow capacity of each of the major engine components. The 5 major turbo-machinery components of a turbofan engine are the fan, low pressure compressor, high pressure compressor, high pressure turbine, and low pressure turbine. Linear estimation techniques, such as the Kalman Filter, can be applied to estimate these parameters given there are as many sensors as parameters to be estimated. For typical aircraft engine applications, 6 to 8 sensors are available to estimate 10 health parameters ( 2 for each of the 5 major turbomachinery components), posing an underdetermined estimation problem. Simon and Garg (Ref. 10), based off the work of Litt (Ref. 11), proposed an approach to optimally select a transformation matrix, $V^{*}$, to minimize the theoretical steady-state estimation error for the engine performance parameters of interest.

The discrete linear time-invariant engine state space equations about a linear design point are:

$$
\begin{gathered}
x_{k+1}=A x_{k}+B u_{k}+L h_{k}+w_{k} \\
y_{k}=C x_{k}+D u_{k}+M h_{k}+v_{k} \\
z_{k}=F x_{k}+G u_{k}+N h_{k}
\end{gathered}
$$

where $k$ is the discrete time index, $x$ is the state vector, $u$ is the control input vector, $y$ is the measured output vector, $z$ is the auxiliary (unmeasured) output vector, $h$ is the health parameter input vector, and $w$ and $v$ are uncorrelated zero-mean white noise inputs. The health parameters, $h$, are unknown inputs to the model and can be treated as a set of biases modeled without dynamics. Therefore, Equation (1) can be re-written in a reduced order form as: 


$$
\begin{gathered}
{\left[\begin{array}{l}
x_{k+1} \\
h_{k+1}
\end{array}\right]=\left[\begin{array}{ll}
A & L \\
0 & I
\end{array}\right]\left[\begin{array}{l}
x_{k} \\
h_{k}
\end{array}\right]+\left[\begin{array}{l}
B \\
0
\end{array}\right] u_{k}+\left[\begin{array}{c}
w_{k} \\
w_{h, k}
\end{array}\right]} \\
y_{k}=\left[\begin{array}{ll}
C & M
\end{array}\right]\left[\begin{array}{l}
x_{k} \\
h_{k}
\end{array}\right]+D u_{k}+v_{k} \\
z_{k}=\left[\begin{array}{ll}
F & N
\end{array}\right]\left[\begin{array}{l}
x_{k} \\
h_{k}
\end{array}\right]+G u_{k}
\end{gathered}
$$

The model tuning parameter, $q$, is constructed as a linear combination of all health parameters, $h$, given by:

$$
q=V^{*} h
$$

The approximation of the health parameter inputs can be obtained as:

$$
\hat{h}=V^{* \dagger} q
$$

Where $V^{* \dagger}$ is the pseudo-inverse of $V^{*}$. Substituting (4) into (2):

$$
\begin{gathered}
{\left[\begin{array}{c}
x_{k+1} \\
h_{k+1}
\end{array}\right]=\left[\begin{array}{cc}
A & L V^{* \dagger} \\
0 & I
\end{array}\right]\left[\begin{array}{l}
x_{k} \\
q_{k}
\end{array}\right]+\left[\begin{array}{l}
B \\
0
\end{array}\right] u_{k}+\left[\begin{array}{c}
w_{k} \\
w_{h, k}
\end{array}\right]} \\
=A_{x q} x_{x q, k}+B_{x q} u_{k}+w_{x q, k} \\
y_{k}=\left[\begin{array}{ll}
C & M V^{* \dagger}
\end{array}\right]\left[\begin{array}{l}
x_{k} \\
q_{k}
\end{array}\right]+D u_{k}+v_{k} \\
=C_{x q} x_{x q, k}+D_{x q} u_{k}+v_{x q, k} \\
z_{k}=\left[\begin{array}{ll}
F & N V^{* \dagger}
\end{array}\right]\left[\begin{array}{l}
x_{k} \\
q_{k}
\end{array}\right]+G u_{k} \\
=F_{x q} x_{x q, k}+G_{x q} u_{k}
\end{gathered}
$$

A Kalman filter is designed for the engine model, or plant, in Equation (5). For the OTKF, steadystate Kalman filtering is applied, which means the Kalman gain $\left(\mathrm{K}_{\infty}\right)$ and state estimation error covariance $\left(\mathrm{P}_{\infty}\right)$ matrices are held constant at each time step. Assuming steady-state open loop operation $(u=0)$, the Kalman filter state estimation takes the following form:

$$
\hat{x}_{x q, k}=A_{x q} \hat{x}_{x q, k-1}+K_{\infty}\left(y_{k}-C_{x q} A_{x q} \hat{x}_{x q, k-1}\right)
$$

The augmented state vector becomes:

$$
\hat{x}_{x h, k}=\left[\begin{array}{cc}
I & 0 \\
0 & V^{*+}
\end{array}\right] \hat{x}_{x q, k}
$$

and the auxiliary state vector becomes:

$$
\hat{z}_{k}=\left[\begin{array}{ll}
F & N V^{* \dagger}
\end{array}\right] \hat{x}_{x q, k}
$$


Reference 10 contains the derivations and detailed information required to calculate the globally optimal transformation matrix. The goal is to find a transformation matrix that is globally optimal for some predefined number of flight conditions throughout the flight envelope. Given a piece-wise linear model, steady-state trim points, and a globally optimized transformation matrix, the matrices, $A_{x q}, B_{x q}, C_{x q}$, $D_{x q}, F_{x q}, G_{x q}$, and $K_{\infty}$ can be calculated and stored, with the trim points, at each linear design point. These values can be recalled by the Kalman filter during run time. In this case, the a priori state estimate becomes:

$$
\hat{x}_{k}^{-}=A_{x q}\left(\hat{x}_{k}^{+}-\Delta x\right)+B_{x q} \Delta u
$$

Where $\Delta x$ is the difference between the current states and the trim states, and $\Delta u$ is the difference between the current measured actuator commands and the expected trim actuator commands. The trim points are a function of the flight condition along with a power reference value, such as corrected fan speed used here. The a posteriori state estimation equation is:

$$
\hat{x}_{k}^{+}=\hat{x}_{k}^{-}+K_{\infty}\left(y_{k}-C_{x q} \hat{x}_{k}^{-}-D_{x q} \Delta u\right)
$$

The output vector and auxiliary vector equations are:

$$
\begin{aligned}
\hat{y}_{k} & =C_{x q} \hat{x}_{k}^{+}+D_{x q} \Delta u \\
\hat{z}_{k} & =F_{x q} \hat{x}_{k}^{+}+G_{x q} \Delta u
\end{aligned}
$$

This implementation has been shown to provide good estimation results (Ref. 10) and are suitable for MBEC (Refs. 1 and 2).

\section{Extended Kalman Filter and Optimal Tuner Kalman Filter Approaches}

The increasing computing power of modern processors is making it feasible to run complex nonlinear models in a Full Authority Digital Electronic Controller (FADEC) in real-time. Relying on a nonlinear model to estimate the engine's unmeasured parameters should result in a reduction of the estimation error of the unmeasured parameters. Typical extended Kalman filters (EKF) rely on partial derivative matrices calculated in real-time from the nonlinear model at the current operating point during operation to calculate the Kalman gain. Even with the increased computing power of modern processors, there are still challenges associated with linearizing the nonlinear engine models in real-time. These challenges include the ability to ensure that the engine model converges at every possible operating point, ensuring that the model converges during the linearization process when the states and inputs are perturbed, and including accommodation techniques for when an invalid nonlinear model is produced. These challenges are even more complicated by ensuring that these procedures can be completed in a fixed amount of time, within a couple of FADEC cycle updates. To avoid these practical issues associated with on-board linearization, a steady-state Kalman filtering approach is considered as implemented with the OTKF. The Kalman gain is calculated off-line, using a piece-wise linear model that is a function of the operating condition, defined as the altitude, Mach number, and power level (corrected fan speed) for a 50 percent deteriorated engine. The Kalman gain can then be stored and recalled as a function of the sensed flight condition.

For the discrete extended Kalman filter implementation, let the a priori estimate be equal to the previous state estimate:

$$
\hat{x}_{k}^{-}=\hat{x}_{k-1}^{+}
$$


Therefore, the a posteriori state estimation equation, Equation (10), can be re-written as:

$$
\hat{x}_{k}^{+}=\hat{x}_{k}^{-}+K_{\infty}\left(y_{k}-\hat{y}_{k}^{-}\right)
$$

where ideally:

$$
\hat{y}_{k}^{-}=C_{x q} \hat{x}_{k}^{-}+D_{x q} \Delta u
$$

This equation shows that $\hat{y}_{k}^{-}$is a function of the a posteriori estimate, $\hat{x}_{k}^{-}$, which is based on the previous estimate. Therefore, in a discrete implementation Equation (13) can be written and implemented as:

$$
\hat{x}_{k}^{+}=\hat{x}_{k}^{-}+K_{\infty}\left(y_{k-1}-\hat{y}_{k-1}^{-}\right)
$$

The update term, $K_{\infty}\left(y_{k-1}-\hat{y}_{k-1}^{-}\right)$which is commonly known as the innovations, is based on the previous output of the nonlinear model and the sensed measurements. Once the estimated a priori state is updated, the nonlinear model is executed based on the current actuator commands, $u_{k}$, and current a posteriori estimate, $\hat{x}_{k}^{+}$, to produce the current output vector, $\hat{y}_{k}$, and auxiliary output vector $\hat{z}_{k}$,:

$$
\begin{aligned}
& \hat{y}_{k}=f\left(\hat{x}_{k}^{+}, u\right) \\
& \hat{z}_{k}=f\left(\hat{x}_{k}^{+}, u\right)
\end{aligned}
$$

This implementation requires the nonlinear model is to be executed only once per time step. For the extended Kalman filter implementation (EKF), the nonlinear engine model is executed assuming a fleet-average 50 percent deteriorated engine and does not require the user to calculate a globally optimal transformation matrix.

Rather than assuming the engine is 50 percent degraded, the extended Kalman filter can be integrated with the optimal tuner state estimate to provide an estimate of the current health of the engine to the nonlinear engine model. This implementation is referred to as the optimal tuner extended Kalman filter (OTEKF). For this implementation, the globally optimal transformation matrix and steady-state Kalman gain from Section II is utilized, since both of these are calculated off-line based on the linear model and stored for run-time. The process for calculating the Kalman gain and globally optimal transformation matrix is the same and it is valid to assume the same results would be produced if the linearization was done online.

In this form, the Kalman filter equations are exactly the same as described for the nonlinear extended Kalman filter (Eqs. (12) to (16)), with the exception that eight tuner states $(q)$ are added to the state estimate vector. $V^{* \dagger}$ is used in the Kalman filter to convert $q$ to the health parameter inputs $h$, as shown in Equation (4), which are inputs to the nonlinear model. The $q$ states are also scaled by the FADEC update rate of $0.015 \mathrm{sec}$ to reduce the impact of the state update. It is assumed that the health parameter inputs have a very slow time constant and will not significantly change during a single flight unless there is a major fault present in the system. Scaling the tuner estimates update helps to reduce the impact of a fuel flow transient on the tuner states, which assumes the fuel flow transient has a large effect on engine degradation. This is due to the observation that the magnitudes of the $q$-states tend to be larger during transients than they are during steady-state. 


\section{Results}

The accuracy of the extended Kalman filter and optimal tuner extended Kalman filter are tested and compared against the original OTKF of the previous MBEC architecture (Refs. 1 and 2). Note that, there are no changes to the controller architecture in this work, only changes to the on-board model Kalman filter. Both the EKF and the OTEKF algorithm rely on the use of a nonlinear engine model to produce the output vector and auxiliary state vector which contains the estimated parameters for the controller as shown in Figure 1 and described in Section III.

One of the potential benefits of MBEC is the ability to reduce the operating margins during the design process and allow the engine designers the ability to move the operating line to a more efficient region to reduce the thrust specific fuel consumption (TSFC) (Ref. 9). In this scenario, the main benefit of MBEC would be observed at cruise. The OTKF, EKF, and OTEKF are implemented and tested using C-MAPSS40k at 100 random cruise flight conditions defined within altitudes of 28,000 to 36,000 ft, 0.4 to $0.8 \mathrm{Mach}$, and for any engine degradation level (0 to 1). At each flight condition, a throttle transient is applied from a cruise setting (power lever angle (PLA 64 to $68^{\circ}$ ), to a flight idle setting (PLA 54 to $60^{\circ}$ ), and back to a slightly higher cruise setting (PLA 64 to $70^{\circ}$ ).

The results of a single flight condition at an altitude of 28,616 ft, 0.736 Mach, with 49.2 percent of life consumed is shown in Figure 2. The top left plot shows the estimated thrust $\left(\mathrm{Fn}_{\mathrm{y}}\right)$, thrust estimation error (Fn) in the top right plot, estimated high pressure turbine inlet temperature (T40y) in the bottom left plot, and high pressure turbine inlet temperature estimation error (T40) in the bottom right plot. The estimation error is the difference between the estimated parameter from the Kalman filter and the engine simulation output. Figure 2 illustrates that the OTKF and EKF have much larger estimation errors during the transients. Figure 2 also shows the large estimation error associated with the extended Kalman filter compared to the OTKF and OTEKF. The results shown in Figure 2 regarding the error of the EKF to both OTKF and OTEKF are consistent, therefore the EKF results will be ignored for the rest of this analysis.
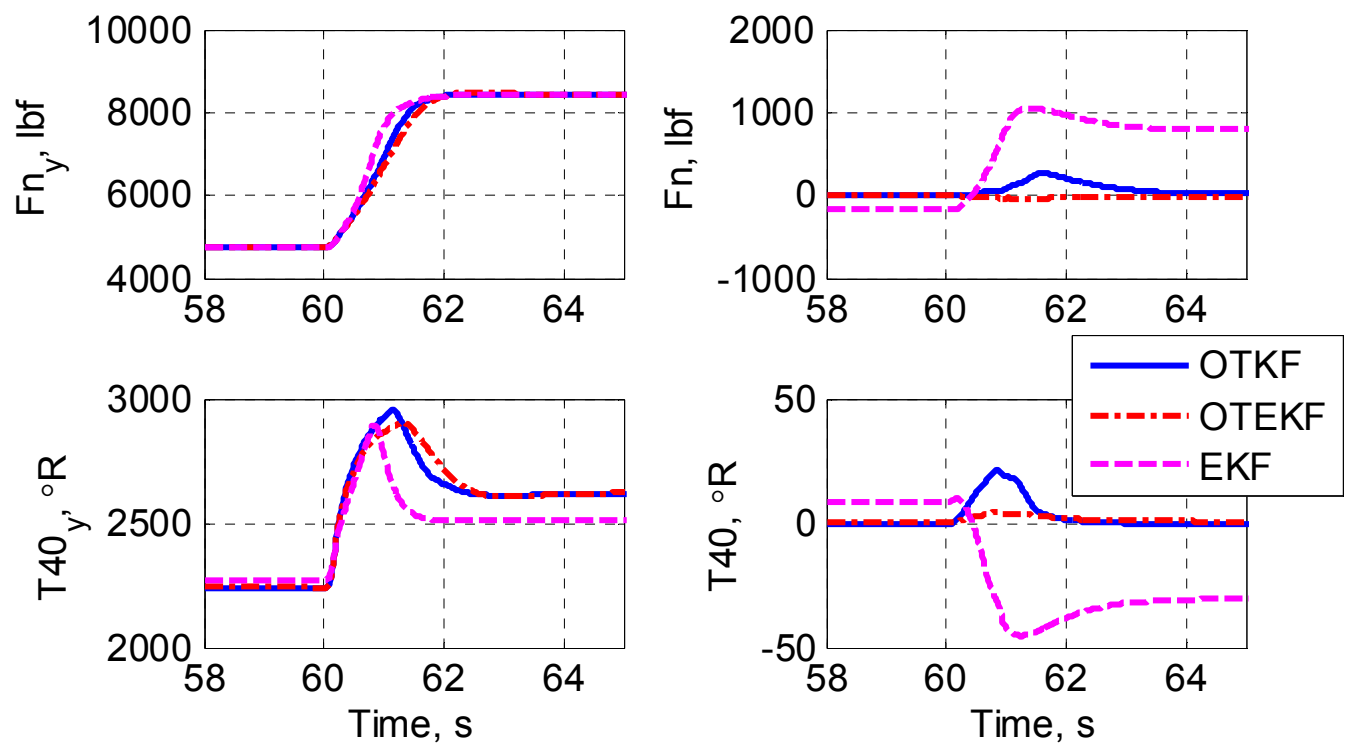

Figure 2.-Comparison of the estimated thrust (top left), estimated T40 (bottom left), thrust estimated error (top right), and T40 estimated error (bottom right) of the three estimation methods at a cruise condition. 
At each flight condition, considering the steady-state cruise and takeoff power levels, the maximum absolute estimation errors for thrust, high pressure compressor surge margin (SM), and high pressure turbine temperatures are shown as a function of the engine degradation level in Figure 3. Figure 3 shows that the OTEKF has the smallest maximum absolute estimation error for the 50 percent degraded engine, which should be expected since $V^{*}$ is optimized for that condition (50 percent degraded). The OTEKF provides better estimation for SM and T40, but slightly worse estimation for thrust.

The absolute maximum estimation error for the thrust, high pressure compressor surge margin, and high pressure turbine temperature are shown in Figure 4 against the flight condition test number. Figure 4 shows that in steady-state, the maximum thrust estimation error is within $150 \mathrm{lb}$, the maximum surge margin estimation is within 0.125 percent, and maximum high pressure turbine estimation error is within $1^{\circ} \mathrm{R}$. Figure 3 and Figure 4 clearly show that in steady-state operation, the OTEKF provides much better estimation of surge margin and high pressure turbine inlet temperature, but does not provide the accuracy in thrust. Re-optimizing the tuner to provide better thrust estimation is possible, however the estimation error in other parameters may increase.

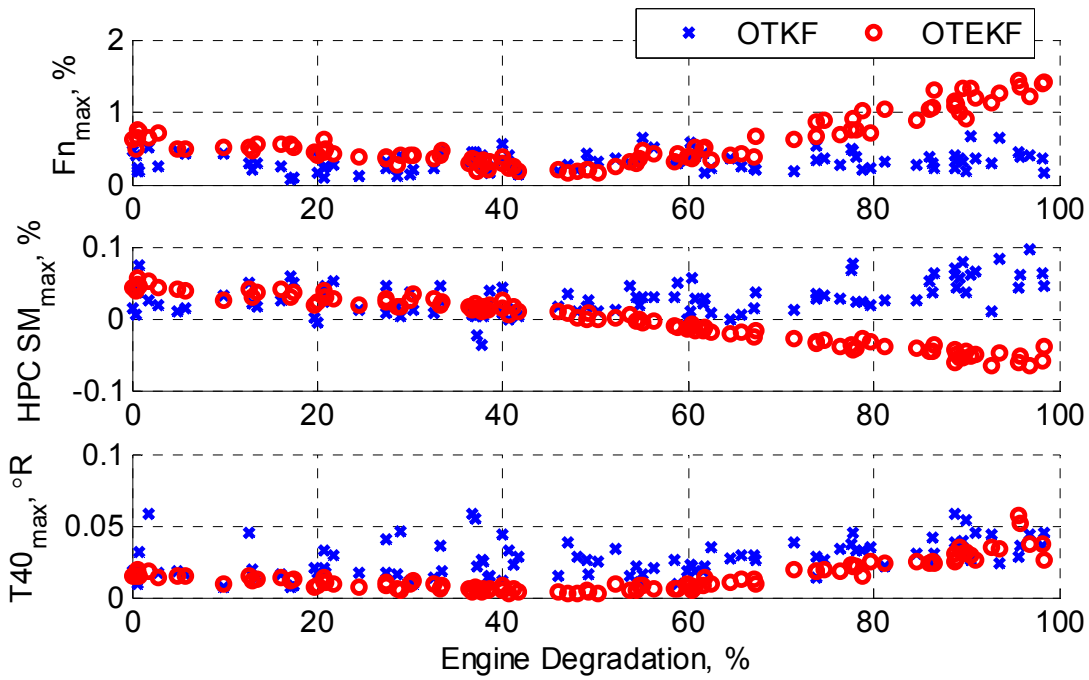

Figure 3.-Comparison of the steady-state maximum absolute estimation errors for thrust (top), surge margin (middle), and T40 (bottom) for the OTKF and OTEKF at cruise flight conditions.

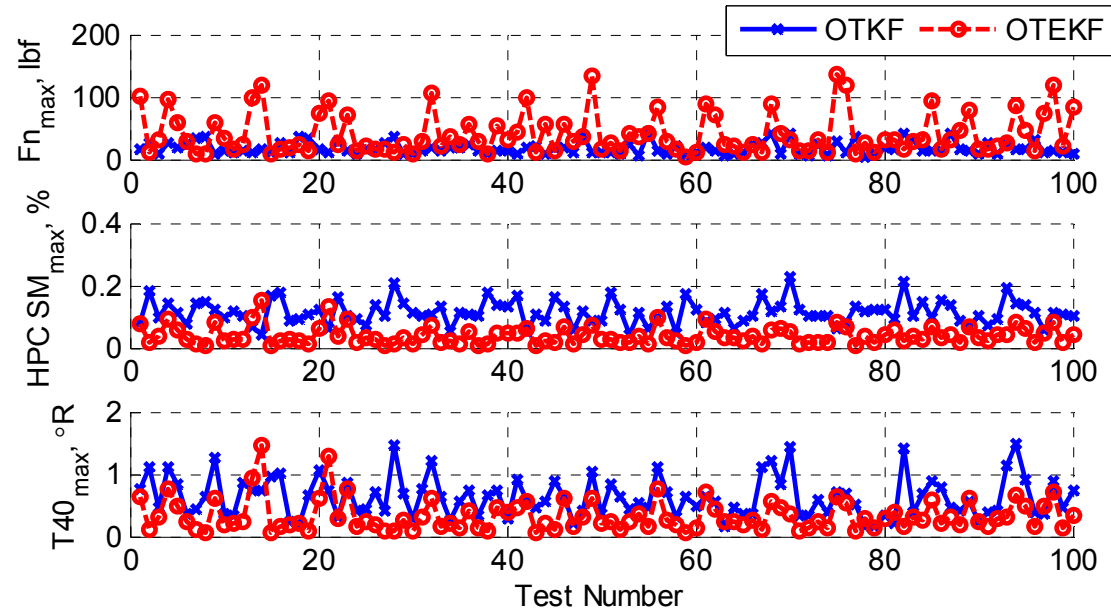

Figure 4.-Comparison of the steady-state maximum absolute estimate error for thrust (top), high pressure compressor surge margin (middle), and high pressure turbine inlet temperature estimation errors. 

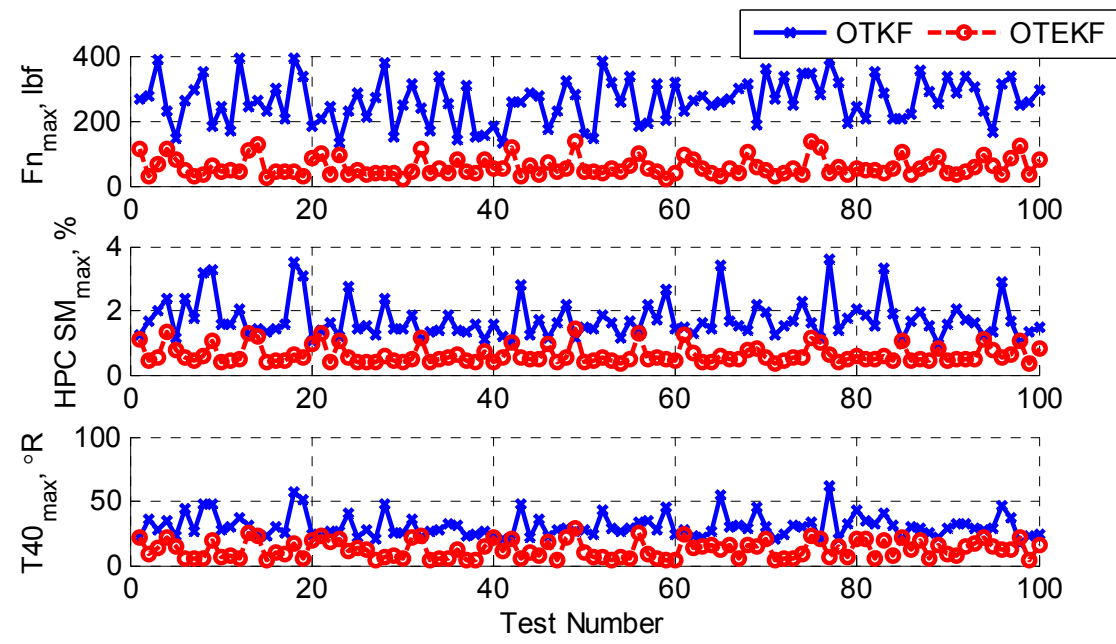

Figure 5.-Plot showing the maximum absolute estimation error for thrust (top), high pressure compressor surge margin (middle), and high pressure turbine inlet temperature during transient operation at cruise flight conditions.

The maximum absolute estimation error for thrust, high pressure compressor surge margin, and high pressure turbine temperature during transient operation is shown in Figure 5. Figure 5 shows that OTEKF provides better estimation during transient operation for thrust and high pressure turbine inlet temperature and relatively as accurate estimation error as OTKF for high pressure compressor surge. The OTEKF provides approximately the same maximum error during transient operation as it does in steady-state, which could be a big advantage. Having a better estimate during the transient allows for tighter control on the estimated parameters of interest, often when they are closest to exceeding a limit. For example, the high pressure turbine inlet temperature tends to overshoot the steady-state point and reaches the maximum value during the transient. In addition, if the estimation values are used for diagnostics, the diagnostic algorithms would not require a scheme to suspend operation during large engine transients.

\section{Conclusions}

Model based engine control (MBEC) is being investigated as a way to increase the efficiency of future aircraft engines by allowing the engine to be designed to operate more efficient without increasing the risk of an engine failure. With accurate information of the current engine operating-conditions and health status, control strategies can be developed that allow the engine to operate more efficiently while avoiding any constraints, such as compressor surge. This work focused on integrating an extended Kalman filter with the previously developed optimal tuner, referred to as the optimal tuner extended Kalman filter (OTEKF). The optimal tuner contains a globally optimized transformation matrix, which relates a set of Kalman filter tuning parameters to health parameter inputs, designed to minimize the theoretical steady-state estimation error for the performance parameters of interest. The estimated health parameters are used as inputs to the nonlinear model and help increase the accuracy of the estimated parameters from the nonlinear model. This paper showed that overall, the OTEKF produced approximately the same average and worst case estimation errors during steady-state operation, but reduced the maximum estimation errors by improving estimation during transient operation. This could allow for further reduction of uncertainty currently included in engine safety margins. 


\section{References}

1. Connolly, J.W., Csank, J.T., Chicatelli, A.K., and Kilver, J., "Model-Based Control of a Nonlinear Aircraft Engine Simulation Using an Optimal Kalman Filter Approach," AIAA-2013-4002, 49 AIAA/ASME/SAE/ASEE Joint Propulsion Conference and Exhibit, San Jose, CA, July 14-17, 2013.

2. Csank, J.T., and Connolly, J.W., "Enhanced Engine Performance During Emergency Operation Using a Model-Based Engine Control Architecture," To Be Presented at 2015 Propulsion and Energy Forum.

3. Jaw, L., and Mattingly, J.D., Aircraft Engine Controls: Design, System Analysis, and Health Monitoring, American Institute of Aeronautics and Astronautics, Inc., VA, 2009.

4. Csank, J.T., May, R.D., Litt, J.S., and Guo, T.-H., "Control Design for a Generic Commercial Aircraft Engine," AIAA-2010-6629, 46 ${ }^{\text {th }}$ AIAA/ASME/SAE/ASEE Joint Propulsion Conference and Exhibit, Nashville, TN, July 25-28, 2010.

5. Spang III, A.H., and Brown, H., "Control of Jet Engines," Control Engineering Practice, 8 March 1999, pp. 1043-1059.

6. May, R.D., Csank, J., Lavelle, T.M., Litt, J.S., and Guo, T.H., “A High-Fidelity Simulation of a Generic Commercial Aircraft Engine and Controller," American Institute of Aeronautics and Aeronautics, Inc., 46 ${ }^{\text {th }}$ Joint Propulsion Conference and Exhibit, Nashville, TN, July 25-28, 2010.

7. Adibhatla, S., and Gastineau, Z., "Tracking Filter Selection and Control Mode Selection for Model Based Control," AIAA 94-3204, 30 ${ }^{\text {th }}$ AIAA/ASME/SAE/ASEE Joint Propulsion Conference, Indianapolis, IN, June 27-29, 1994.

8. KrishnaKumar, K., Hachisako, Y., and Huang, Y., "Jet Engine Performance Estimation Using Intelligent System Technologies," AIAA-2001-1122, 39 ${ }^{\text {th }}$ AIAA Aerospace Sciences Meeting \& Exhibit, Reno, NV, January 8-11, 2001.

9. Viassolo, D.E., Adibhatla, S., Brunell, B.J., Down, J.H., Gibson, N.S., Kumar, A., Mathews, K., and Holcomb, L.D., "Advanced Estimation for Aircraft Engines," ThAT05.1, Proceedings of the 2007 American Control Conference, New York, NY, July 11-13, 2007.

10. Simon, D.L., and Garg, S., "Optimal Tuner Selection for Kalman Filter-Based Aircraft Engine Performance Estimation,” ASME, Journal of Gas Turbines and Power, Vol. 132, March, 2010.

11. Litt, J.S., "An Optimal Orthogonal Decomposition Method for Kalman Filter-Based Turbofan Engine Thrust Estimation," AMSE, Journal of Gas Turbines and Power, Vol. 130, 2008. 

